\title{
Correction to: Adaptive coordinated control strategy for multi-terminal flexible DC transmission systems with deviation control
}

Mingwan Mei ${ }^{1} \cdot$ Ping Wang ${ }^{1} \cdot$ Yanbo Che ${ }^{1} \cdot$ Chao Xing ${ }^{1,2}$

Published online: 21 June 2021

(c) The Korean Institute of Power Electronics 2021

\section{Correction to: \\ Journal of Power Electronics (2021) 21:724-734 \\ https://doi.org/10.1007/s43236-021-00219-7}

Due to an unfortunate oversight the funding note has been given erroneously. It should read: This work was supported by the National Key Research and Development Project of China (2017YFB0903000).

The original article can be found online at https://doi.org/10.1007/ s43236-021-00219-7.

Yanbo Che

lab538@163.com

1 Key Laboratory of Smart Grid of Education Ministry, Tianjin University, Tianjin, China

2 Electric Power Research Institute of Yunnan Power Grid Co., Ltd., Kunming, China 